Jurnal Agro 7(1), 2020

\title{
DAYA HASIL DAN INDEKS PANEN UBI JALAR UNGGUL BARU BERDAGING KUNING (Ipomoea batatas L. (Lam.))
}

\section{YIELD AND HARVEST INDEX ON NEW SUPERIOR GENOTYPES OF YELLOW-FLESHED SWEET POTATO (Ipomoea batatas L. (Lam.))}

\author{
Agung Karuniawan ${ }^{1,2 *}$, Reviana Aulia ${ }^{2}$, Haris Maulana ${ }^{1}$, Debby Ustari ${ }^{1}$ dan Neni Rostini ${ }^{1}$ \\ ${ }^{1}$ Departemen Budidaya Pertanian, Fakultas Pertanian, Universitas Padjadjaran \\ Jl. Raya Bandung Sumedang KM.21, Sumedang 45363 \\ ${ }^{2}$ Program Studi Magister Manajemen Sumberdaya Hayati, Sekolah Pascasarjana, Universitas \\ Padjadjaran, Jl. Raya Dipati Ukur No. 35, Bandung 40132
}

Korespondensi : agung.karuniawan@unpad.ac.id

Diterima : 16 Agustus 2019 / Disetujui : 2 Juli 2020

\begin{abstract}
ABSTRAK
Estimasi daya hasil dan indeks panen dalam pemuliaan tanaman dibutuhkan untuk menyeleksi genotip ubi jalar. Genotip ubi jalar terseleksi yang berdaya hasil tinggi dapat digunakan sebagai bahan pendukung diversifikasi pangan. Tujuan dari penelitian ini adalah untuk memperoleh genotip ubi jalar berdaya hasil tinggi serta memiliki indeks panen tinggi. Penelitian dilaksanakan di Kebun Percobaan Fakultas Pertanian Universitas Padjadjaran Kabupaten Sumedang, Jawa Barat dari bulan November 2018 sampai April 2019. Penelitian ini menggunakan delapan genotip ubi jalar dan tiga genotip pembanding (Ac Putih, Kidal, dan Rancing). Metode yang digunakan adalah rancangan acak kelompok (RAK) dengan 11 perlakuan yang diulang sebanyak tiga kali. Hasil penelitian menunjukkan bahwa jumlah ubi per tanaman, jumlah ubi total, jumlah ubi ekonomis, bobot ubi per tanaman, bobot ubi total dan bobot ubi ekonomis menunjukan perbedaan yang nyata. Terdapat tujuh genotip yang berdaya hasil tinggi yaitu MZ 332, PR 91 (838), Awachy 4, KMDK, IND 38 (48), IND 8 (11), IND 264. Terdapat empat genotip ubi jalar unggul baru yang memiliki hasil indeks panen $>1$ yaitu, Mz 332, PR 91(838), KMDK, dan IND 8(11).
\end{abstract}

Kata kunci: daya hasil, indeks panen, komponen hasil, ubi jalar

\begin{abstract}
Estimation of yield and harvest index on sweet potato are needed to select new superior genotypes of sweet potato in the breeding program. Selected sweet potato genotypes with high yield can be used as supporting material for food diversification. The purpose of this study was to obtain new superior genotypes of yellow-fleshed sweet potato with high yield and high harvest index. The study was conducted in the Experimental field, Faculty of Agriculture, Universitas Padjadjaran, Sumedang Regency, West Java from November 2018 to April 2019. This study used eight sweet potato genotypes as treatment and three genotypes as check i.e. Ac Putih, Kidal and Rancing. The method used was randomized block design (RBD) with 11 treatments repeated three times. The results showed that the numbers of tuber per plant, numbers of tuber per plot, numbers of economic tuber, weight of tuber per
\end{abstract}

Cyte this as: Karuniawan, A., Aulia, R., Maulana, H., Ustari, D. \& Rostini, N. (2020). Daya hasil dan indeks panen ubi jalar unggul baru berdaging kuning (Ipomoea batatas L. (Lam.)). Jurnal Agro, 7(1), 24-31. https://doi.org/10.15575/5704 
plant, total weight per plot, weight of economic tubers were significantly different. There are seven genotypes with the high yield, i.e. MZ 332, PR 91 (838), Awachy 4, KMDK, IND 38 (48), IND 8 (11), IND 264. Four genotypes with harvest index > 1 i.e. Mz 332, PR 91 (838), KMDK, and IND 8 (11).

Keyword: yield, harvest index, yield traits, sweet potato

\section{PENDAHULUAN}

Jawa Barat merupakan sentra produksi ubi jalar. Menurut Mahmudatussa'adah (2014), salah satu sentra produksi ubi jalar di Indonesia adalah Provinsi Jawa Barat. Mustamu et al. (2018) juga menyebutkan bahwa Jawa Barat merupakan wilayah sentra produksi ubi jalar sehingga dapat dijadikan wilayah untuk menyeleksi ubi jalar berdasarkan stabilitas hasil. Berdasarkan hal tersebut maka wilayah Jawa Barat dapat dijadikan lokasi pengujian untuk identifikasi komponen hasil ubi jalar.

Produksi ubi jalar di Jawa Barat mengalami fluktuasi setiap tahunnya. Pada tahun 2013 mencapai $485.065 \mathrm{t}$ tahun 2014 menurun menjadi $471.737 \mathrm{t}$, tahun 2015 menurun kembali menjadi 456.156 t. Pada tahun 2016 mengalami peningkatan menjadi $523.201 \mathrm{t}$, namun menurun kembali di tahun 2017 menjadi $477.828 \mathrm{t}$ dan meningkat di tahun 2018 produksi mencapai 547.879 t (BPS, 2018). Salah satu faktor tidak stabilnya produksi adalah rendahnya penggunaan varietas berdaya hasil tinggi. Jumlah verietas unggul ubi jalar masih tergolong sedikit dibandingkan dengan komoditas lainnya. Hal ini menunjukan bahwa peningkatan produksi ubi jalar di Jawa Barat perlu didukung oleh program pemuliaan tanaman.

Ubi jalar merupakan salah satu bahan pangan yang banyak dikonsumsi masyarakat Jawa Barat. Menurut penelitian Mahmudatussa'adah (2014), kandungan utama ubi jalar yaitu karbohidrat. Anggraeni \& Yuwono (2014), menyebutkan bahwa ubi jalar juga mengandung vitamin, mineral, dan menyediakan energi sebesar 123 per 100 g. Pada penelitian Widyaningtyas dan Susanto (2015), menyebutkan bahwa ubi jalar memiliki kandungan karbohidrat yang tinggi setelah beras, jagung, dan ubi kayu. Oleh karena itu, ubi jalar sangat baik digunakan sebagai bahan pangan masyarakat Jawa Barat.

Salah satu jenis ubi jalar yang sering dimanfaatkan masyarakat yaitu ubi jalar kuning. Keunggulan dari ubi jalar kuning adalah mengandung betakaroten yang tinggi daripada labu kuning dan setara dengan wortel (Ginting et al., 2014). Ubi jalar kuning mengandung pula betakaroten tinggi pada kultivar dengan daging ubi berwama kuning hingga oranye. Semakin tinggi intensitas warna oranye, maka kadar betakarotennya semakin tinggi (Saraswati et al., 2013). Hal tersebut menunjukan bahwa mengkonsumsi ubi jalar kuning dapat menambah asupan vitamin A yang bermanfaat bagi tubuh.

Komponen hasil merupakan karakter yang paling penting dalam komoditas pertanian. Menurut Putri et al. (2013), komponen hasil dimanfaatkan untuk menyeleksi klon harapan ubi jalar. Hakim (2012) juga menyatakan bahwa komponen hasil dan indeks panen (HI) dapat dimanfaatkan pada proses seleksi untuk memperoleh genotip unggul. Dengan demikian, seleksi genotip unggul baru dapat diestimasi melalui karakter hasil tanaman.

Indeks panen atau Harvest Indeksx (HI) mencerminkan indikasi distribusi relatif dari hasil asimilasi antara ubi dengan bagian 
tanaman lainnya. Menurut Zuraida (2010), HI ditentukan berdasarkan rasio hasil (ubi) dan hasil biologis (daun dan sulur). Putri et al. (2013) menyebutkan bahwa produktivitas tanaman ubi kayu dapat dilihat dari indeks panen.

Sebanyak 8 genotip ubi jalar yang digunakan dalam penelitian ini merupakan hasil seleksi dari hasil polycross dan hand pollination. Tetua betina yang dipakai pada persilangan adalah hasil eksplorasi dari beberapa daerah di Indonesia termasuk diantaranya dari provinsi Jawa Barat. Saat ini, informasi mengenai komponen hasil dan indeks panen 8 genotip ubi jalar baru di Jawa Barat belum diketahui. Informasi tersebut perlu diketahui untuk dapat menyeleksi genotip-genotip unggul harapan baru yang memiliki hasil lebih baik daripada varietas cek atau pembanding. Penelitian ini bertujuan untuk mengestimasi komponen hasil dan indeks panen ubi jalar berdaging kuning di Jawa Barat.

\section{BAHAN DAN METODE}

\section{Bahan Penelitian}

Bahan yang digunakan terdiri dari delapan genotip ubi jalar baru yaitu: $M Z$ 332, PR 91 (838), Awachy 4, KMDK, IND 38 (48), IND 8 (11), IND 264, dan IND 463, serta tiga varietas cek sebagai pembanding yaitu, Ac Putih, Kidal, dan Rancing. Genotip-genotip tersebut merupakan $F_{1}$ hasil persilangan Laboratorium Teknologi Benih dan Pemuliaan Tanaman Fakultas Pertanian Universitas Padjadjaran. Pupuk kandang yang digunakan adalah kotoran ayam dengan dosis $5 \mathrm{t}$ ha $^{-1}$ yang diaplikasikan pada awal penanaman. Pupuk NPK mutiara diaplikasikan pada umur 6 MST setelah tanam dengan dosis $200 \mathrm{~kg}$ ha-1.

\section{Rancangan lapangan}

Percobaan lapangan menggunakan Rancangan Acak Kelompok (RAK) yang menggunakan 11 perlakuan dan diulang sebanyak tiga kali. Penelitian dilakukan di Kebun Percobaan Ciparanje, Fakultas Pertanian Universitas Padjadjaran, Kecamatan Jatinangor, Kabupaten Sumedang. Lokasi mempunyai jenis tanah Inseptisol yang berada pada ketinggian 752 $\mathrm{m}$ dpl. Setiap genotip ditanam dalam plot berukuran $5 \times 5 \mathrm{~m}^{2}$ yang berupa guludan dengan tinggi $40 \mathrm{~cm}$ dan lebarnya $70 \mathrm{~cm}$. Panjang setiap guludan adalah $5 \mathrm{~m}$. Sehingga setiap genotip ditanam sebanyak 5 guludan. Bahan tanam yang digunakan yaitu stek batang berukuran $25 \mathrm{~cm}$.

Pupuk dasar yang digunakan adalah pupuk kotoran ayam. Dosis yang digunakan 5 t ha ${ }^{-1}$ dan diaplikasikan pada saat pengolahan lahan. Pemupukan susulan dilakukan pada saat tanaman berumur 6 MST. Dalam penelitian ini tidak dilakukan pengamatan hama. Panen dilakukan pada saat tanaman berumur 18 MST. Panen dilakukan dengan cara digali menggunakan cangkul.

\section{Koleksi data}

Karakter komponen hasil yang diamati yaitu jumlah ubi pertanaman, jumlah ubi total, jumlah ubi ekonomis, bobot ubi pertanaman, bobot ubi total, dan bobot ubi ekonomis, serta bobot brangkasan (Huaman, 1999). Sampel tanaman diambil sebanyak tiga tanaman dari 125 tanaman dalam setiap plot. Karakter yang dihitung pada tiga sampel tanaman yaitu, jumlah ubi pertanaman, bobot ubi pertanaman, dan berangkasan. Karakter jumlah ubi total, jumlah ubi ekonomis, bobot ubi total, dan bobot ubi ekonomis dihitung berdasarkan total tanaman dalam satu plot. Perhitungan bobot ubi pertanaman, bobot ubi total, dan bobot ubi ekonomis dilakukan dengan cara menimbang sampel menggunakan 
timbangan analitik sedangkan untuk jumlah ubi pertanaman, jumlah ubi total, dan jumlah ubi ekonomis dengan cara menghitung langsung jumlah ubinya.
Pemilihann ubi jalar ekonomis mengikuti Maulana et al. (2016a) tersaji pada tabel 1. dengan spesifikasi sebagai berikut:

Tabel 1. Standar Ubi Jalar Ekonomis

\begin{tabular}{llll}
\hline Ukuran & Besar & Sedang & Kecil \\
\hline Panjang $(\mathrm{cm})$ & $18-22$ & $15-20$ & $10-15$ \\
Diameter $(\mathrm{cm})$ & $5-7$ & $3-5$ & $3-4$ \\
Berat $(\mathrm{gram})$ & $250-400$ & $200-250$ & $150-250$ \\
\hline
\end{tabular}

\section{Analisis data}

Untuk mengestimasi variasi komponen (ANOVA) mengikuti Gomez dan Gomez hasil menggunakan analisis varians (1984):

Tabel 2. Analisis Varians Rancangan Acak Kelompok

\begin{tabular}{lccccc}
\hline SumberVariasi & $\mathrm{db}$ & $\mathrm{JK}$ & $\mathrm{KT}$ & Fhit & Ftabel \\
\hline Ulangan $(\mathrm{r})$ & $\mathrm{r}-1$ & $\mathrm{JKK}$ & $\mathrm{JKK} /(\mathrm{r}-1)$ & KTK/KTG & \\
Perlakuan $(\mathrm{t})$ & $\mathrm{t}-1$ & $\mathrm{JKP}$ & $\mathrm{JKP} /(\mathrm{t}-1)$ & KTP/KTG & \\
Galat & $(\mathrm{r}-1)(\mathrm{t}-1)$ & JKG & $\mathrm{JKG} /(\mathrm{r}-1)(\mathrm{t}-1)$ & & \\
Total & $\mathrm{tr}-1$ & $\mathrm{JKT}$ & & & \\
\hline
\end{tabular}

Keterangan:

$r=$ ulangan $; t=$ perlakuan $; d b=$ derajat bebas $; \mathrm{KT}=$ Kuadrat Tengah.

Untuk menguji keunggulan perlakuan dengan varietas ceknya menggunakan $\mathrm{Uji}$ Least Significant Increase (LSI) mengikuti (Petersen, 2016):

$$
\mathrm{LSI}=\mathrm{t} \alpha \sqrt{\frac{2 \mathrm{KTG}}{\mathrm{n}}}
$$

Keterangan: $\mathrm{t} \alpha=$ Nilai $\mathrm{t}$ tabel satu arah derajat bebas dari KTG; $\mathrm{n}=$ Banyaknya ulangan; KTG = Kuadrat nilai tengah galat

Untuk mengestimasi Indeks panen (HI) mengikuti Amao et al. (2018):

$$
\mathrm{HI}=\frac{\mathrm{TW}}{\mathrm{TBW}}
$$

Keterangan:

TW = hasil ubi total ; TBW = total biomassa (bobot brangkasan + ubi)

\section{HASIL DAN PEMBAHASAN}

Variasi karakter komponen hasil ubi jalar berdaging kuning

Hasil analisis varians terhadap komponen hasil tersaji dalam Tabel 3. Tabel tersebut menunjukan bahwa semua karakter komponen hasil berbeda nyata. Hal ini menunjukan bahwa terdapat perbedaan antar setiap perlakuan pada karakter komponen hasil. Perbedaan karakter komponen hasil dari setiap perlakukan disebabkan oleh perbedaan genetik dari setiap genotip yang diuji. Setiap genotip merupakan hasil persilangan dari tetua-tetua yang berbeda asal usulnya. Selain itu, perbedaan beberapa sumber tetua asal yang di introduksi dari peru dan mozambik juga menjadi salah satu faktor tersebut.

Wahyuni et al. (2016) melaporkan bahwa perbedaan karakter komponen hasil 
pada tanaman ubi jalar disebabkan oleh faktor genotip, lingkungan, dan interaksi antara keduanya. Pada penelitian lainnya Karuniawan et al. (2017) melaporkan bahwa perbedaan karakter komponen hasil pada tanaman singkong disebabkan oleh perbedaan asal wilayah genotip yang digunakan. Mustamu et al. (2018) juga melaporkan bahwa perbedaan karakter hasil pada ubi jalar yang diuji di Jawa Barat disebabkan oleh faktor genotip dan interaksi genotip dan lingkungan. Maka dari itu, perlu dilakukan pengujian lanjut terhadap karakter komponen hasil yang diuji untuk melihat perbedaan antar setiap perlakuan.

Tabel 3. Hasil Analisis Varians Rancangan Acak Kelompok

\begin{tabular}{clccc}
\hline No & Karakter & Rata-rata & Fhitung & KV (\%) \\
\hline 1 & Jumlah ubi per tanaman & 2,93 & $5,86^{*}$ & 12,29 \\
2 & Bobot ubi per tanaman (kg) & 0,49 & $5,91^{*}$ & 11,45 \\
3 & Jumlah ubi ekonomis (per plot) & 7,30 & $5,72^{*}$ & 41,00 \\
4 & Bobot ubi ekonomis (kg/plot) & 1,43 & $10,06^{*}$ & 24,24 \\
5 & Jumlah ubi total (per plot) & 52,21 & $6,45^{*}$ & 16,60 \\
6 & Bobot ubi total (kg/plot) & 5,51 & $7,41^{*}$ & 15,08 \\
7 & Berangkasan (Kg/tanaman) & 0,79 & 1,77 & 20,44 \\
\hline
\end{tabular}

Keterangan: (*) Nilai F hitung berbeda nyata dengan $\mathrm{F}$ tabel pada taraf $5 \%$

Tabel 3. menyajikan nilai koefisien variasi (KV) pada rentang 11,45 sampai 41,00. Semakin kecil koefisien variasi maka derajat ketelitian semakin tinggi. Menurut Andrade et al. (2016), nilai KV dibawah $10 \%$ tergolong kecil, 10-20\% tergolong sedang, dan lebih dari $20 \%$ tergolong tinggi. Terdapat empat karakter yang nilai KVnya tergolong sedang yaitu karakter jumlah ubi pertanaman, bobot ubi pertanaman, jumlah ubi total, dan bobot ubi total. Tiga karakter lainnya yaitu jumlah ubi ekonomis, bobot ubi ekonomis, dan brangkasan yang nilai KVnya tergolong tinggi disebabkan oleh nilai galatnya yang besar karena interaksi lingkungan dan genotipnya luas.

Pada Tabel 4 tersaji hasil uji LSI terhadap karakter komponen hasil. Pengujian dilakukan ketika hasil analisis varians menunjukan perbedaan yang nyata $(p>0,05)$. Berdasarkan tabel tersebut pada karakter jumlah ubi pertanaman terdapat enam genotip yang melebihi varietas cek Kidal yaitu genotip $\mathrm{Mz}$ 332, PR 91 (838), Awachy 4, KMDK, IND 38(48), dan IND $8(11)$, sedangkan dua genotip lainnya IND
264 dan IND 463 tidak melebihi varietas cek.

Pada karakter jumlah ubi ekonomis terdapat satu genotip yang melebihi varietas cek Ac Putih yaitu genotip IND 8(11), sedangkan tujuh genotip lainnya tidak melebihi varietas cek. Pada karakter jumlah ubi total terdapat enam genotip yang melebihi varietas cek Ac Putih dan Kidal yaitu Mz 332, PR 91 (838), KMDK, IND 38(48), IND 8 (11), dan IND 264. Genotip Awachy 4 hanya melebihi varietas cek Kidal, sedangkan satu genotip lainnya tidak melebihi varietas cek yaitu genotip IND 463.

Pada karakter bobot ubi pertanaman terdapat tiga genotip yang melebihi varietas cek Ac Putih dan Kidal yaitu PR 91(838), KMDK, dan 8(11). Genotip Mz 332 hanya melebihi varietas cek Ac Putih, sedangkan empat genotip lainnya tidak melebihi varietas cek. Pada karakter bobot ubi ekonomis terdapat satu genotip yang melebihi varietas cek Ac Putih dan Kidal yaitu genotip 8(11), sedangkan tujuh genotip lainnya tidak melebihi varietas cek. Pada karakter bobot ubi total terdapat 
enam genotip yang melebih varietas cek $A c$ Putih dan Kidal yaitu Mz 332, PR 91(838), Awachy 4, KMDK, 38(48), dan 8(11). Genotip 264 dan 463 melebihi varietas cek Kidal dan tidak ada genotip yang melebihi varietas cek Rancing. Menurut Maulana et al. (2016) genotip yang sudah melebihi setengah varietas cek dikatakan unggul. Berdasarkan hal tersebut genotip-genotip yang melebihi dua varietas cek merupakan genotip yang unggul.

Tabel 4. Hasil Uji Least Significant Increase (LSI) Terhadap Karakter Hasil dan Komponen Hasil Ubi Jalar Berdaging Kuning di Jatinangor

\begin{tabular}{|c|c|c|c|c|c|c|}
\hline GENOTIP & JUP & BUP (kg) & JUE & BUE (kg) & JUT & BUT (kg) \\
\hline MZ 332 & $3,22 \mathrm{~b}$ & $0,58 a$ & 6,67 & 1,09 & $48,00 a b$ & 35,45 \\
\hline PR 91 (838) & $2,78 \mathrm{~b}$ & $0,62 a b$ & 6,00 & 1,03 & $41,67 a b$ & 30,24 \\
\hline Awachy 4 & $3,33 \mathrm{~b}$ & 0,35 & 1,00 & 0,31 & $26,33 b$ & 26,60 \\
\hline KMDK & $3,56 \mathrm{~b}$ & $0,62 a b$ & 8,00 & 2,03 & $62,67 a b$ & 29,63 \\
\hline $38(48)$ & $3,00 \mathrm{~b}$ & 0,23 & 6,33 & 0,83 & $51,33 a b$ & 25,05 \\
\hline $8(11)$ & $4,00 \mathrm{~b}$ & $0,92 a b$ & $15,67 a$ & $3,27 a b$ & $88,00 a b$ & 53,81 \\
\hline 264 & 2,44 & 0,20 & 2,67 & 0,24 & $49,67 a b$ & 14,06 \\
\hline 463 & 1,78 & 0,12 & 0,00 & 0,00 & 8,00 & 14,74 \\
\hline Nilai LSI & 1,72 & 0,28 & 7,37 & 2,33 & 1,95 & 1,32 \\
\hline CEK1+LSI & 4,72 & 0,58 & 11,70 & 2,97 & 40,29 & 19,79 \\
\hline CEK2+LSI & 2,56 & 0,60 & 8,03 & 2,43 & 11,29 & 8,72 \\
\hline CEK3+LSI & 6,05 & 1,48 & 36,37 & 8,58 & 152,95 & 76,44 \\
\hline
\end{tabular}

Keterangan: 1) Cek 1 = Ac Putih; Cek 2 = Kidal; Cek 3 = Rancing.

2) JUP= Jumlah ubi Pertanaman; BUP = Bobot ubi Pertanaman; JUE = Jumlah ubi Ekonomis; BUE = Bobot ubi Ekonomis; JUT = Jumlah ubi Total; BUT = Bobot ubi Total.

3) $a=$ melebihi cek $1 ; b=$ melebihi cek 2 .

Indeks Panen Ubi Jalar Berdaging Kuning

Tabel 5 menunjukan hasil pengujian indeks panen pada sebelas genotip ubi jalar berdaging kuning. HI yang dihasilkan berada pada rentang 0,53 - 2,21. hasil tertinggi terdapat pada genotip Rancing sedangkan yang paling kecil adalah genotip 463. Berdasarkan hal tersebut terdapat enam genotip yang hasilnya lebih dari satu yaitu genotip Mz 332, PR 91(838), KMDK, 8(11), Kidal, dan Rancing.

Tabel 5. Hasil Analisis Indeks Panen terhadap genotip ubi jalar berdaging kuning di Jatinangor

\begin{tabular}{|c|c|c|c|c|c|}
\hline No. & Genotip & $\begin{array}{l}\text { Rata-Rata Bobot ubi } \\
\text { Pertanaman (kg) }\end{array}$ & $\begin{array}{l}\text { Rata-Rata Bobot } \\
\text { Brangkasan (kg) }\end{array}$ & Indeks Panen & Keterangan \\
\hline 1. & MZ 332 & 0,58 & 1,37 & 1,01 & Tinggi \\
\hline 2. & PR 91 (838) & 0,62 & 1,09 & 1,18 & Tinggi \\
\hline 3. & Awachy 4 & 0,35 & 0,67 & 0,86 & Rendah \\
\hline 4. & KMDK & 0,62 & 1,21 & 1,13 & Tinggi \\
\hline 5. & $38(48)$ & 0,23 & 0,61 & 0,62 & Rendah \\
\hline 6. & $8(11)$ & 0,92 & 1,24 & 1,66 & Tinggi \\
\hline 7. & Ac Putih & 0,30 & 0,50 & 0,90 & Rendah \\
\hline 8. & Kidal & 0,32 & 0,29 & 1,42 & Tinggi \\
\hline 9. & Rancing & 1,20 & 1,19 & 2,21 & Tinggi \\
\hline 10. & 264 & 0,20 & 0,34 & 0,80 & Rendah \\
\hline 11. & 463 & 0,12 & 0,29 & 0,53 & Rendah \\
\hline
\end{tabular}


Indeks panen adalah kemampuan tanaman menyalurkan asimilat. Jika indeks panen tinggi $(>1)$, maka distribusi hasil asimilasi lebih besar ke pembesaran ubi, sebaliknya jika indeks panen rendah $(<1)$ menunjukan asimilat ke ubi lebih kecil. Suminarti \& Susanto (2015) mengemukakan bahwa semakin tinggi nilai indeks panen maka semakin tinggi pula bobot ubi pertanaman dan potensi hasilnya. Penelitian Hakim (2012) juga melaporkan bahwa semakin tinggi indeks panen maka semakin tinggi juga hasil biji kedelai yang dihasilkan. Oleh sebab itu, $H$ l yang diharapkan dari pengujian adalah yang lebih dari satu agar didapatkan genotip berdaya hasil tinggi.

\section{SIMPULAN}

Terdapat tujuh genotip yang berdaya hasil tinggi yaitu MZ 332, PR 91 (838), Awachy 4, KMDK, IND 38 (48), IND 8 (11), dan IND 264. Empat genotip unggul baru yang memiliki indeks panen lebih dari satu (tinggi) yaitu Mz 332, PR 91(838), KMDK, dan IND 8(11).

\section{Ucapan terima kasih}

Penelitian ini didanai oleh RISPRO LPDP yang diberikan kepada Dr. Ir. M.Sc. Agr. Agung Karuniawan, M.Sc.Agr. dari Fakultas Pertanian Universitas Padjadjaran.

\section{DAFTAR PUSTAKA}

Amao, P.A., S.O. Osunsanya, \& A.M. Afolabi. (2018). Yield Evaluation and Assessment of Growth of Five Different Varieties of Sweet Potato (Ipomoea batatas ( L .) Lam ). Journal of Agriculture and Ecological Research Intemational. 15(1): 1-8. doi: 10.9734/JAERI/2018/40744.

Andrade, Maria I., Abdul Naico, Jose' Ricardo, Rau 'I Eyzaguirre, Godwill S.
Makunde, Rodomiro Ortiz, W.J.Grueneberg. (2016). Genotype x Environment Interaction and Selection for Drought Adaptation in Sweet potato (Ipomoea batatas [L .] Lam .) in Mozambique. Euphytica 209: 261-280.doi:10.1007/s10681-016-168 4-4.

Anggraeni, Y.P., \& S.S. Yuwono. (2014). Pengaruh Fermentasi Alami Pada Chips Ubi Jalar (Ipomoea batatas) Terhadap Sifat Fisik Tepung Ubi Jalar Terfermentasi. Jurnal Pangan dan Agroindustri 2(2): 59-69.

BPS. (2018). Luas Panen, Produktivitas, dan Produksi Ubi Jalar di Indonesia. https://www.bps.go.id/subject/53/tan aman-pangan.html\#subjekViewTab3.

Ginting, E., R. Yulifianti, \& M. Jusuf. (2014). Ubijalar Sebagai Bahan Diversifikasi Pangan Lokal. Jurnal Pangan 23(2): 194-207.

Gomez, K.A., \& A.A. Gomez. (1984). Statistical Procedures for Agricultural Research (Gomez \& Gomez, 1984). 1st ed. John Wiley \& Sons, Ltd, New York.

Hakim, L. (2012). Komponen Hasil dan Karakter Morfologi Penentu Hasil Kedelai. Penelitian Pertanian Tanaman Pangan 31(3): 173-179.

Huaman, Z. (1999). Sweetpotato Germplasm Management (Ipomoea batatas) Training Manual. Intrenational Potato Center (CIP).

Karuniawan, A., N. Wicaksono, D. Ustari, T. Setiawati, \& T. Supriatun. (2017). Identifikasi keragaman genetik plasma nutfah ubi kayu liar (Manihot glaziovii muell) berdasarkan karakter morfo-agronomi. Jurnal Kultivasi. 16(3): 435-443.

Mahmudatussa'adah, A. (2014). Komposisi Kimia Ubi Jalar. Jurnal Pangan 23(1): 
53-64.

Maulana, H., D.M. Nugroho, L. Trimo, \& A. Karuniawan. (2016a). Participatory selection of sweet potato based on farmers preferences in banjar city. Proceedings of SABRAO 13th Congress and International Congress. IPB Press, Bogor

Maulana, H., M. Rachmadi, \& A. Karuniawan. (2016b). Respon Klon Serta Potensi Hasil Ubi Jalar Pada Dua Lokasi Sentra Tanam di Jawa Barat. Prosiding. Semin. Nas. PERIPI Komda Riau "Strategi Pemuliaan Dalam Mengantisipasi Perubahan Iklim Glob. Pekanbaru.

Mustamu, Yohanis Amos, Koko Tjintokohadi, Wolfgang J. Grüneberg, Agung Karuniawan, \& D.Ruswandi. (2018). Selection of superior genotype of sweet-potato in Indonesia based on stability and adaptability. Chilean Journal of Agricultural Research. 78(4): $\quad 461-469 . \quad$ doi: 10.4067/S0718-58392018000400461.

Petersen, R.G. (2016). Agricultural Field Experiments: Design and Analysis. CRC Press, New York.

Putri, D.I., Sunyoto, E. Yuliadi, \& S.D. Utomo. (2013). Keragaman Karakter Agronomi Klon-Klon F1 Ubi Kayu (Manihot esculenta Crantz) Keturunan Tetua Betina UJ-3, CMM 25-27, dan Mentik Urang. Jurnal Agrotek Tropika. 1(1): 1-7.

Saraswati, P., A. Soplanit, A.T. Syahputra, L. Kossay, N. Muid, E. Ginting, G. Lyons. 2013. Yield trial and sensory evaluation of sweet potato cultivars in Highland Papua and West Papua Indonesia. Journal of Tropical Agriculture. 51(1): 74-83.

Suminarti, N.E., \& Susanto. 2015. Pengaruh Macam dan Waktu Aplikasi Bahan Organik Matter Pada Tanaman Ubi
Jalar (Ipomea batatas L.) Var. Kawi. J. Agro 2(1): 15-28.

Wahyuni, T.S., J. Restuono, \& F.C. Indriani. (2016). Pengaruh Turun Gulud terhadap Hasil dan Komponen Hasil Klon Ubi Jalar di Lahan Kering Masam. Prosiding. Seminar Hasil Penelitian Tanaman. Aneka Kacang dan ubi. Malang. 550-558.

Widyaningtyas, M., \& W.H. Susanto. (2015). Pengaruh Jenis dan Konsentrasi Hidrokoloid (Carboxy Methyl Cellulose, Xanthan Gum, dan Karagenan) Terhadap Karakteristik Mie Kering Berbasis Pasta Ubi Jalar Varietas Ase Kuning. Jurnal Pangan dan Agroindustri 3(2): 417-423.

Zuraida, N. (2010). Karakterisasi Beberapa Sifat Kualitatif dan Kuantitatif Plasma Nutfah Ubi Kayu (Manihot esculenta Crantz .). Buletin Plasma Nutfah 16(1): 49-56. 